\title{
Effect of ACE, ACE2 and CYP11B2 gene polymorphisms and noise on essential hypertension among steelworkers in China: a case-control study
}

Xiaohong Zhang ${ }^{1}$, Ying Wang ${ }^{2}$, Yao Zheng ${ }^{3}$, Juxiang Yuan ${ }^{1}$, Junwang Tong ${ }^{1 *}$, Jingya X ${ }^{1}$, Qinglin Li ${ }^{1}$, Peishuai Li ${ }^{1}$, Shoufang Jiang ${ }^{1}$, Zhaoyang Wang ${ }^{4}$, Feng Chai ${ }^{1}$ and Xiangwen $\mathrm{Li}^{1}$

\begin{abstract}
Background: Previous studies on the relationship between ACE I/D, ACE2 G8790A and CYP11B2-344T/C gene polymorphisms and essential hypertension (EH) were inconsistent. Moreover, few studies have reported the combined effect of these gene polymorphisms and noise exposure on $\mathrm{EH}$. The purpose of this study was to explore the combined and separate effects of ACE I/D, ACE2 G8790A and CYP11B2-344T/C gene polymorphisms and noise on EH among steelworkers.

Methods: A case-control study was conducted on 725 male workers between March 2014 and July 2014 in the Tangsteel Company, China. The noise exposure of the workers were measured. Logistic regression and crossover analysis were used to analyse the effects of the interactions on the EH among steelworkers. GMDR was used to determine the best combination model of gene-noise interactions.

Results: Multivariate logistic regression showed that noise exposure increased the odds of $E H$, and the OR is 1.52 (95\% Cl 1.04-2.22). The risk of having EH for ACE I/D DD genotype carriers was 1.99 times that for II genotype carriers (95\% CI 1.14-3.51). There was a negative additive interaction between ACE2 G8790A and CYP11B2-344T/C on $\mathrm{EH}(\mathrm{U} 3=-2.221, P=0.026$, and $\mathrm{S}=0.128)$ and a positive multiplicative interaction between $A C E \mathrm{I} / \mathrm{D}$ and CYP11B2$344 \mathrm{~T} / \mathrm{C}$ on essential hypertension $(P=0.041)$. In addition, there was no significant gene-noise interaction model through the GMDR method after adjusting the confounders.
\end{abstract}

Conclusions: The ACE DD genotype may make men susceptible to EH. Simultaneously carrying the DD genotype of ACE I/D and the TC genotype of CYP11B2-344T/C increased the risk of EH.

Keywords: Essential hypertension, Noise, Gene polymorphism, Interaction, GMDR

*Correspondence: junwangtong@yeah.net

${ }^{1}$ School of Public Health, North China University of Science

and Technology, No. 21 Bohai Avenue, Caofeidian Area, Tangshan 063210,

Hebei Province, People's Republic of China

Full list of author information is available at the end of the article

\section{Background}

Essential hypertension (EH) is one of the most common cardiovascular diseases and is affected by a variety of genetic and environmental factors [1]. In recent decades, the prevalence of hypertension among Chinese adults has risen sharply, making it a public health problem that cannot be ignored [2]. Noise is common in workplaces in the steel industry. Previous studies 
have shown that noise can increase plasma renin, angiotensin II and aldosterone concentrations in the body, causing excessive activation of the renin-angiotensinaldosterone system (RAAS) [3], thereby promoting the occurrence and development of hypertension [4]. The RAAS plays an important role in regulating human blood pressure. RAAS genes are the most likely susceptibility genes for essential hypertension $[5,6]$, such as angiotensin-converting enzyme, angiotensin-converting enzyme 2, and aldosterone synthase. Studies have shown that the ACE I/D polymorphism [7], the ACE2 G8790A polymorphism [8], and the CYP11B2$344 \mathrm{~T} / \mathrm{C}$ polymorphism [9] are related to the occurrence of hypertension. However, some studies have yielded inconsistent results $[10,11]$, and few studies have reported the interaction of ACE polymorphism, ACE2 polymorphism, CYP11B2 polymorphism with noise exposure on hypertension. In this study, a case-control study was carried out among steelworkers, in whom the interactions between noise exposure and the ACE I/D, ACE2 G8790A, and CYP11B2-344T/C polymorphisms were analysed. The effects of gene-gene interactions on EH were also analysed.

\section{Methods}

\section{Study population}

A case-control study was conducted in Tangsteel Company in Tangshan, China. In the study, the selected subjects were male workers who participated in the occupational health examination of the steel company between March 2014 and July 2014.

$\mathrm{EH}$ was diagnosed according to the preventive report of the seventh US Joint National Committee on Detection, Evaluation and Treatment of Hypertension (JNC 7) as the diagnostic criteria [12], combined with the workers' medical history and the history of taking hypertension medication. Inclusion criteria for the case group: (1) the patient was diagnosed with $\mathrm{EH}$ according to the diagnostic criteria; (2) was a Han male worker who was 18 years old or older; and (3) had worked at the Tangsteel Company for at least 1 year. Exclusion criteria: (1) the participant had a history of liver or kidney disease, diabetes, secondary hypertension, or other cardiovascular diseases; (2) was exposed to high temperatures; or (3) had been employed in a different line of work before. Those in the control group were diagnosed as non-hypertensive according to the same diagnostic criteria, and the other inclusion and exclusion criteria were the same as those in the case group. A total of 725 subjects were eventually included; among them, 224 were in the case group and 501 were in the control group.

$$
\begin{aligned}
& n=\frac{\left[z_{\propto} \sqrt{2 \bar{p}(1-\bar{p})}+z_{\beta} \sqrt{p_{1}\left(1-p_{1}\right)+p_{0}\left(1-p_{0}\right)}\right]^{2}}{\left(p_{1}-p_{0}\right)^{2}} \\
& \bar{p}=\frac{\left(p_{1}+p_{0}\right)}{2} \\
& p_{1}=\frac{\left(O R \times p_{0}\right)}{\left(1-p_{0}+O R \times p_{0}\right)}
\end{aligned}
$$

$p_{0}$ : The exposure rate of control group;

$p_{0}$ : The exposure rate of case group.

In this study, we initially screened the data according to the National Center for Biotechnology Information (NCBI) Single Nucleotide Polymorphism (SNP) database (http://www.ncbi.nlm.nih.gov/SNP) and the minimum allele frequency (MAF) of the selected SNP locus was 0.216 . We calculated the sample size and followed by the conditions: $\alpha=0.05, \beta=0.10$, expected $\mathrm{OR}=2.0$, and the calculated sample size is 218 in the case group and control group, respectively. The present sample size is enough.

This study was approved by the Ethics Committee of North China University of Science and Technology, and all the subjects voluntarily signed an informed consent form.

\section{Questionnaire and assessment of covariates}

In this study, uniformly trained personnel surveyed all the research subjects in face-to-face interviews that followed a uniform questionnaire. The contents of the questionnaire mainly included: (1) general demographic information, including age, sex, height, weight, marital status, education level and family income; (2) occupation history, including working-age and shift; (3) lifestyle and eating habits, including smoking (never smoked vs. had quit or still smoked), drinking (never drank vs. had quit or still drank), fried food, meat, whole grains, fruit, vegetable intake and physical exercise $(<3$ times/week is less, $\geq 3$ times/week is more); (4) psychological stress, including work, family, economic and emotional stress (sometimes with or without being light, periodic or always being heavy); and (5) personal disease history and family history of hypertension.

The subjects of the study were examined by a group of uniformly trained researchers according to the standard of the instrument, including height, weight, blood pressure, heart rate and electrocardiogram. Then the body mass index (BMI) was calculated as weight $(\mathrm{kg})$ divided by the height squared $\left(\mathrm{m}^{2}\right)$.

Venous blood of the workers was collected from the anterior elbow, anticoagulated with EDTA, and stored in a refrigerator at $-80^{\circ} \mathrm{C}$ for DNA extraction and biochemical analysis. The total cholesterol (TC) and triglyceride (TG) in the serum were measured. 


\section{Determination of noise and high-temperature exposure}

Noise exposure of the workplace was measured using a sound analyser (TES-1350A; TES Electronic Corp, Taiwan). Time-weighted average (TWA) noise defined a worker's occupational noise exposure time of $8 \mathrm{~h}$ per day or $40 \mathrm{~h}$ of work per week based on the time spent in each location and the average noise level. In our study, the 40-h TWA level was calculated from the worker's staying time in the workplace and the shift situation. If the noise exposure was greater than or equal to $80 \mathrm{~dB}(\mathrm{~A})$, the subjects were judged to be noise-exposed. According to Zhao et al. [13], cumulative noise exposure (CNE) was calculated as follows:

$$
C N E=10 \times \log \left(\sum 10^{0.1 \times \mathrm{L}(\mathrm{A}) \mathrm{eq}} \times \text { the years of noise exposure }\right)
$$

The temperature of the workplace was measured with a wet bulb global temperature (WBGT) analyser (QT-36; Quest Technologies Corp, America) in July and August 2014, the two hottest months of the year. The temperature of different workspaces was detected, from which each worker's WBGT value was calculated. In this study, if the WBGT was greater than or equal to $25{ }^{\circ} \mathrm{C}$ and the subjects were exposed to productive heat sources, they were judged to be high-temperature workers.

\section{ACE I/D, ACE2 G8790A, CYP11B2-344T/C gene polymorphism detection}

The DNA of the blood sample was extracted by using a whole-blood rapid genomic DNA extraction kit (Beijing Aid Lab Biotechnology Co, Ltd.). Gene polymorphisms were typed by restriction fragment length polymorphism (RFLP) techniques and polymerase chain reaction (PCR). The total volume of the amplification reaction was $25 \mu \mathrm{l}$, including 12.5 $\mu \mathrm{l}$ PCR Taq Master Mix, $1.0 \mu \mathrm{l}$ upstream primer, $1.0 \mu \mathrm{l}$ downstream primer, $1.0 \mu \mathrm{l}$ DNA template, and $9.5 \mu \mathrm{l}$ deionized water.

Primers for PCR were designed using the Primer 5.0 software package (Beijing Ruiboxingke Biotechnology Co, Ltd.). The primer sequences and PCR conditions of each gene locus are shown in Additional file 1: Table S1 and Table S2 in the supplement file, and each PCR product needed to be digested with restriction enzymes (Additional file 1: Table S2). Because ACE I/D is an insertion/deletion site, the genotyping results could be seen by directly observing the amplification products of PCR (Fig. 1). The PCR products of ACE2 G8790A and CYP11B2-344T/C were reacted with the AluI endonuclease (NEB Corp, American) and the HaeIII endonuclease (NEB Corp, American) in a water bath at $37{ }^{\circ} \mathrm{C}$ for $3 \mathrm{~h}$, electrophoresed on a
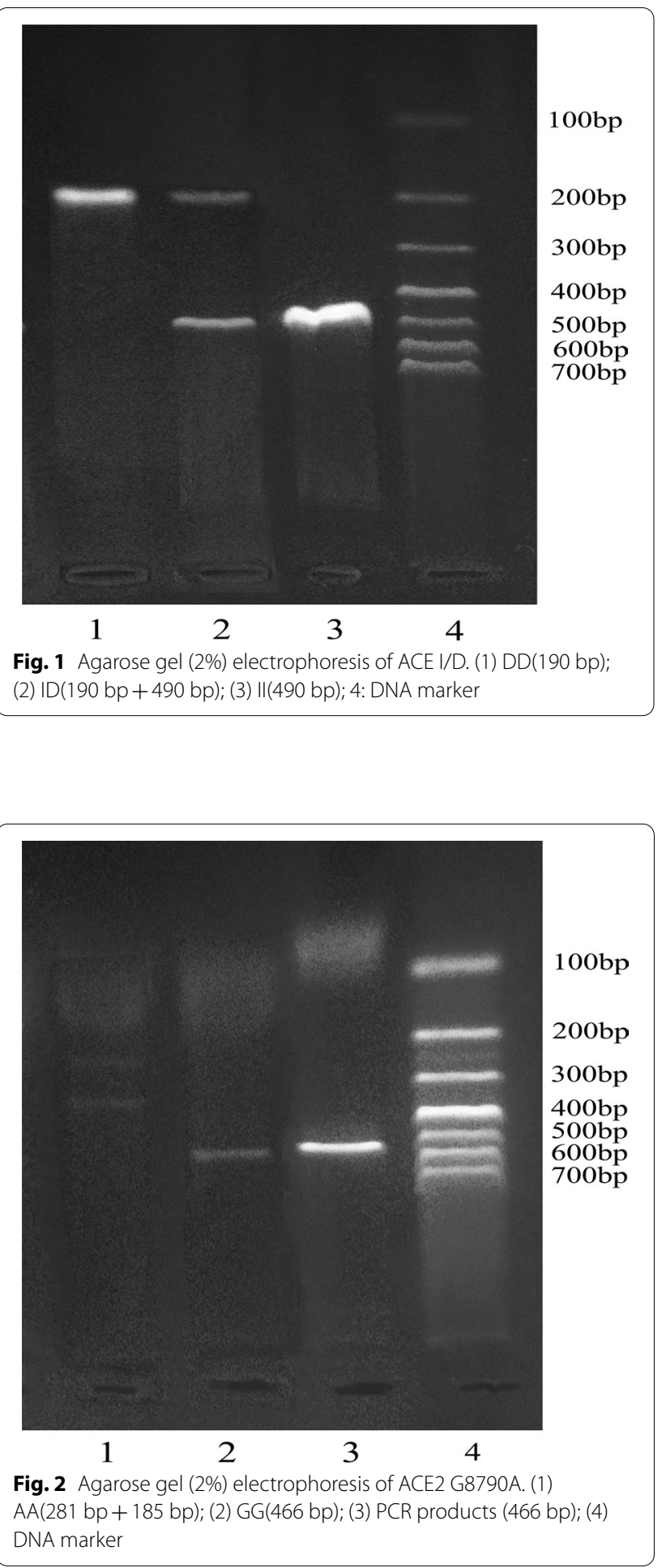

$2.0 \%$ agarose gel and stained with ethidium bromide. Genetic polymorphisms were detected with an ultraviolet analyser, as shown in Fig. 2 and Fig. 3. 


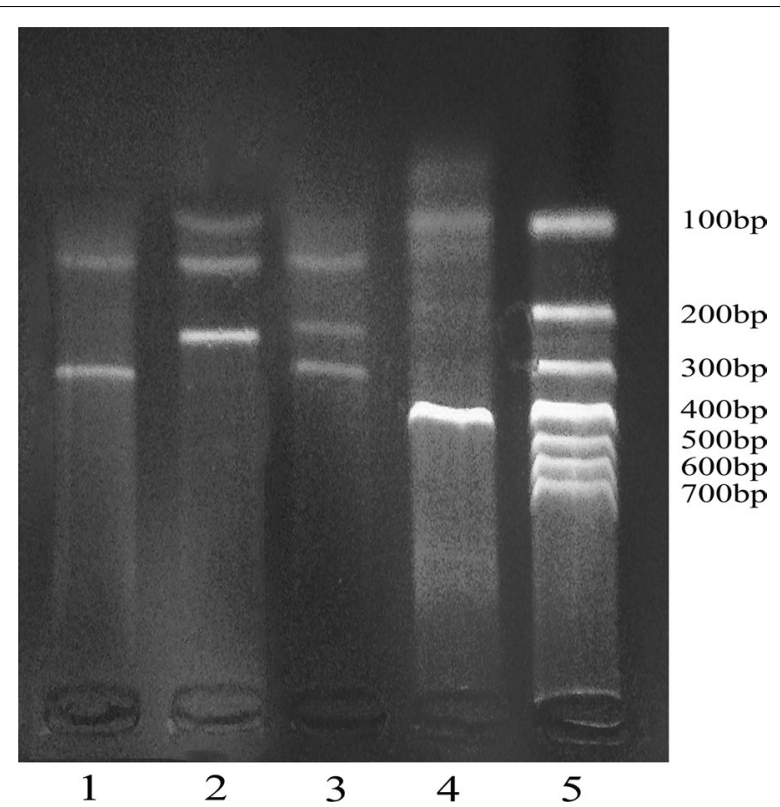

Fig. 3 Agarose gel (2\%) electrophoresis of CYP11B2-344T/C. (1) TT(116 bp + $283 \mathrm{bp}) ;(2) \mathrm{CC}(71 \mathrm{bp}+116 \mathrm{bp}+212) ;(3)$ TC(71 bp + $116 b p+212 b p+283 b p) ;(4)$ PCR product; (5) DNA marker

\section{Statistical analyses}

For the comparison of continuous baseline characteristics, Student's t test or Wilcoxon's rank sum test was used. For categorical variables, the chi-square test was used for comparison. The Hardy-Weinberg equilibrium (HWE) test and comparison of the distribution of alleles and genotypes between the case and control groups were performed with the chi-squared test. The effects of the interaction between gene and gene and between gene and noise based on multiplicative and additive models on $\mathrm{EH}$ were investigated by logistic regression and the crossover analytical method proposed by Rothman et al. [14]. Generalized multifactor dimensionality reduction (GMDR, 0.9) was used to determine the best-combined model of the interaction between genes and noise. Analyses were conducted with SPSS 23.0 (SPSS Inc., Chicago, IL, USA) with a two-sided significance threshold of $P<0.05$.

\section{Results}

\section{Comparison between workers of the EH group and control group}

Comparing the two groups, the percentage of workers exposed to noise in the EH group (42.0\%) was significantly higher than that in the control group (31.6\%) $(P<0.05)$. The percentage of workers with a family history of hypertension in the EH group (43.4\%) was significantly higher than that in the control group $(29.2 \%)(P<0.01)$. The percentage of obesity in the EH group (35.3\%) was higher than that in the control group (12.0\%), and the distribution of BMI between the two groups was significantly different $(P<0.05)$. Age, length of service, TC and TG in the EH group were significantly higher than those in the control group $(P<0.05)$. The percentage of the $\mathrm{EH}$ group (18.4\%) with a university education and above was significantly lower than that of the control group (33.2\%) $(P<0.01)$. The percentages of workers who regularly did physical exercise and regularly ate vegetables in the $\mathrm{EH}$ group were lower than those in the control group $(P<0.05)$. The other factors, including marital status, shift work, smoking and drinking, were not significantly different, as shown in Table 1.

The genotype distributions at ACE I/D, ACE2 G8790A, and CYP11B2-344T/C in the control group all complied with the Hardy-Weinberg equilibrium law. Compared with the control group, the EH group had a significantly different ACE I/D genotype distribution $(P<0.05)$. The percentage of the $\mathrm{D}$ allele in the $\mathrm{EH}$ group was significantly higher than that in the control group $(P<0.05)$. Because ACE2 G8790A is on the X chromosome, men only have the GG genotype or AA genotype. There was no statistically significant difference in the genotype distribution of ACE2 G8790A in the EH group. The percentage of the A allele in the $\mathrm{EH}$ group was significantly higher than that in the control group $(P<0.05)$. There was no statistically significant difference in the genotype percentage or allele percentage of CYP11B2-344T/C between groups see Additional file 1: Table S3.

\section{Multivariate logistic regression analysis of the relationship between environmental factors, gene polymorphisms and $\mathrm{EH}$}

The statistically significant indicators in the univariate logistic regression analysis were input as independent variables and $\mathrm{EH}$ was taken as the dependent variable to perform multiple logistic regression analysis to eliminate the influence of confounding factors.

The risk of having EH for ACE I/D DD genotype carriers was 1.99 times that for II genotype carriers (95\% CI 1.14-3.51), which suggested that the DD genotype may be a susceptibility genotype for $\mathrm{EH}$. The genetic polymorphisms CYP11B2-344T/C and ACE2 G8790A showed no association with essential hypertension (Table 2).

\section{Analysis of gene-gene interactions}

From Table 3, the hypothesis testing of the interaction showed that ACE I/D and CYP11B2-344T/C showed no interaction in the additive model $(\mathrm{U}=1.769, P=0.076)$. ACE and ACE2 G8790A also did not have any interaction based on the additive model ( $\mathrm{U} 2=-0.401, P=0.688)$. ACE2 G8790A and CYP11B2-344T/C had an interaction based on the additive model ( $\mathrm{U} 3=-2.221, P=0.026)$. 
Table 1 Comparison of the baseline data between workers of EH group and control group

\begin{tabular}{|c|c|c|c|c|c|}
\hline Factors & Case, $\mathrm{n}(\%)$ & EH group $(n=224)$ & Control group $(n=501)$ & $t / X^{2} / U$ & $P$ \\
\hline Noise, n (\%) & & & & 7.422 & 0.006 \\
\hline No & 473 & $130(58.0)$ & $343(68.4)$ & & \\
\hline Yes & 252 & $94(42.0)$ & $158(31.6)$ & & \\
\hline BMI $\left(\mathrm{kg} / \mathrm{m}^{2}\right), \mathrm{n}(\%)$ & & & & 72.117 & $<0.001$ \\
\hline$<24$ & 265 & $42(18.7)$ & $223(44.5)$ & & \\
\hline $24-27$ & 321 & $103(46.0)$ & $218(43.5)$ & & \\
\hline$\geq 28$ & 139 & $79(35.3)$ & $60(12.0)$ & & \\
\hline Marriage, n (\%) & & & & 3.458 & 0.063 \\
\hline No & 67 & $14(6.2)$ & $53(10.5)$ & & \\
\hline Yes & 658 & $210(93.8)$ & $448(89.5)$ & & \\
\hline Education, n (\%) & & & & 16.69 & $<0.001$ \\
\hline Below university & 518 & $183(81.6)$ & $335(66.8)$ & & \\
\hline University and above & 207 & $41(18.4)$ & $166(33.2)$ & & \\
\hline Income, n (\%) & & & & 1.126 & 0.289 \\
\hline$<3000$ & 538 & $172(76.7)$ & $366(73.0)$ & & \\
\hline$\geq 3000$ & 187 & $52(23.3)$ & $135(27.0)$ & & \\
\hline Current shift status, n (\%) & & & & 0.311 & 0.577 \\
\hline No & 224 & $66(29.4)$ & $158(31.5)$ & & \\
\hline Yes & 501 & $158(70.6)$ & $343(68.5)$ & & \\
\hline Family history of hypertension, $\mathrm{n}(\%)$ & & & & 13.932 & $<0.001$ \\
\hline No & 482 & $127(56.6)$ & $355(70.8)$ & & \\
\hline Yes & 243 & $97(43.4)$ & $146(29.2)$ & & \\
\hline Smoking & & & & 0.952 & 0.329 \\
\hline No & 314 & $91(40.6)$ & $223(44.5)$ & & \\
\hline Yes & 411 & $133(59.4)$ & $278(55.5)$ & & \\
\hline Drinking & & & & 2.494 & 0.114 \\
\hline No & 582 & $172(76.7)$ & $410(81.8)$ & & \\
\hline Yes & 143 & $52(23.3)$ & $91(18.2)$ & & \\
\hline Eat fried food & & & & 2.364 & 0.124 \\
\hline$<3$ times/week & 644 & $205(91.5)$ & $439(87.6)$ & & \\
\hline$\geq 3$ times/week & 81 & $19(8.5)$ & $62(12.4)$ & & \\
\hline Eat meat & & & & 1.667 & 0.197 \\
\hline$<3$ times/week & 421 & $138(61.7)$ & $283(56.4)$ & & \\
\hline$\geq 3$ times/week & 304 & $86(38.3)$ & $218(43.6)$ & & \\
\hline Eat whole grains & & & & 0.110 & 0.741 \\
\hline$<3$ times/week & 591 & $181(80.8)$ & $410(81.8)$ & & \\
\hline$\geq 3$ times/week & 134 & $43(19.2)$ & $91(18.2)$ & & \\
\hline Eat vegetable & & & & 5.094 & 0.024 \\
\hline$<3$ times/week & 139 & $54(24.2)$ & 85 (16.9) & & \\
\hline$\geq 3$ times/week & 586 & $170(75.8)$ & $416(83.1)$ & & \\
\hline Eat fruit & & & & 0.785 & 0.376 \\
\hline$<3$ times/week & 274 & $90(40.1)$ & $184(36.7)$ & & \\
\hline$\geq 3$ times/week & 451 & $134(59.9)$ & $317(63.3)$ & & \\
\hline Physical exercise & & & & 5.019 & 0.025 \\
\hline$<3$ times/week & 166 & $63(28.2)$ & $103(20.6)$ & & \\
\hline$\geq 3$ times/week & 559 & $161(71.8)$ & $398(79.4)$ & & \\
\hline Work pressure & & & & 0.005 & 0.945 \\
\hline Smaller & 448 & $138(61.6)$ & $310(61.8)$ & & \\
\hline Larger & 277 & $86(38.4)$ & $191(38.2)$ & & \\
\hline
\end{tabular}


Table 1 (continued)

\begin{tabular}{|c|c|c|c|c|c|}
\hline Factors & Case, n (\%) & EH group $(n=224)$ & Control group $(n=501)$ & $t / x^{2} / U$ & $P$ \\
\hline Family pressure & & & & 0.138 & 0.710 \\
\hline Smaller & 626 & $195(87.0)$ & $431(86.0)$ & & \\
\hline Larger & 99 & $29(13.0)$ & $70(14.0)$ & & \\
\hline Economic pressure & & & & 0.620 & 0.431 \\
\hline Smaller & 533 & $169(75.4)$ & $364(72.6)$ & & \\
\hline Larger & 192 & $55(24.6)$ & $137(27.4)$ & & \\
\hline Emotional stress & & & & 0.545 & 0.460 \\
\hline Smaller & 693 & $216(96.4)$ & $477(95.2)$ & & \\
\hline Larger & 32 & $8(3.6)$ & $24(4.8)$ & & \\
\hline Age (years) & & $40.86 \pm 8.15$ & $36.98 \pm 8.08$ & $41,213.500$ & $<0.001$ \\
\hline Length of service & & $20.58 \pm 9.45$ & $16.35 \pm 9.17$ & $41,478.000$ & $<0.001$ \\
\hline $\mathrm{TG}(\mathrm{mmol} / \mathrm{L})$ & & $1.76(1.34,2.26)$ & $1.36(0.98,2.06)$ & $41,926.500$ & $<0.001$ \\
\hline $\mathrm{TC}(\mathrm{mmol} / \mathrm{L})$ & & $4.90(4.30,5.60)$ & $4.70(4.10,5.30)$ & $48,575.000$ & 0.004 \\
\hline
\end{tabular}

BMI, body mass index; $\mathrm{EH}$, essential hypertension; $\mathrm{TC}$, total cholesterol; $\mathrm{TG}$, triglyceride

Among them, the synergy index $S=0.128$, and there seemed to be a negative interaction between the two; the absolute value of the attribution proportion of the interaction (AP) was 0.856 ; the absolute value of the relative excess risk of interaction (RERI) was 0.979; and the interaction odds ratio $\left(\mathrm{OR}_{\mathrm{INT}}\right)=0.485$. $\mathrm{EH}$ was taken as the dependent variable, and each gene and its interaction terms were introduced into the logistic regression equation to analyse the influence of the interactions between ACE, ACE2 and CYP11B2 in the effect on EH based on the multiplicative model after adjustment for confounders such as BMI, family history of hypertension, TG, and TC.

As shown in Additional file 1: Table S4, ACE I/D and CYP11B2-344T/C showed an interaction based on the multiplicative model $(P<0.05)$; the risk of having $\mathrm{EH}$ for dual ACE I/D DD and CYP11B2-344T/C TC genotype carriers were 3.04 times that for dual ACE I/D II genotype and CYP11B2-344T/C TT genotype carriers (95\% CI 1.25-7.39). The remaining interactions were not significant based on the multiplicative model in this study.

\section{Analysis of gene-noise interaction}

From Table 4, The hypothesis testing of the interaction showed that none of the three genes showed an interaction with noise based on the additive model (ACE: $\mathrm{U}=-0.067, \quad P=0.946 ; \quad$ ACE2: $\mathrm{U}=-0.289$, $P=0.772$; CYP: $\mathrm{U}=-0.896, P=0.370$ ).

Taking EH as the dependent variable, multiple-factor logistic regression analysis was used to analyse the influence of the interactions between ACE, ACE2, CYP11B2 and noise on $\mathrm{EH}$ based on the multiplicative model after adjustment for BMI, family history of hypertension, TG, TC and other confounders. None of the three genes showed an interaction with noise based on the multiplicative model see Additional file 1: Table S5.

\section{GMDR analysis of gene-noise interactions}

The results showed that the four-factor model composed of ACE, ACE2, CYP genes and noise was the best model. The cross-validation consistency was $10 / 10$, the test balance accuracy was 0.5084 , and $P=0.3770$. Therefore, we found no significant gene-noise interaction combinations after adjusting for covariates $(P>0.05)$, as shown in Table5. The cells intuitively reflect the gene-noise interaction see additional file 1 Figure S1.

\section{Discussion}

The aetiology of EH is very complicated, and it is affected by a variety of genes, environmental factors, and their interactions. Its mechanism of action has not been ascertained so far.

Studies have found that the RAAS plays an important role in the regulation of blood pressure, the maintenance of water and salt balance, and the remodeling of cardiovascular tissues [15]. ACE is an important rate-limiting enzyme of RAAS. Agachan et al. [16] conducted a casecontrol study on $109 \mathrm{EH}$ patients and 86 non-EH patients and found that the frequency of the D allele in the EH group was significantly higher than that in the control group. ACE2 can negatively regulate the RAAS system. Studies have shown that the ACE2 G8790A polymorphism is correlated with $\mathrm{EH}$, and the risk of $\mathrm{EH}$ in people carrying the $\mathrm{G}$ allele is relatively high [8]. CYP11B2 is an important catalytic enzyme for the synthesis of aldosterone, which generates aldosterone by catalysing its production from deoxycorticosterone through a multistep reaction [17]. Studies have shown that both the $C$ allele 
Table 2 Multiple logistic regression analysis of the relationship between noise exposure, gene polymorphisms and EH

\begin{tabular}{|c|c|c|c|}
\hline Factors & Genotype & OR $(95 \% \mathrm{Cl})$ & $O R^{\mathrm{a}}(95 \% \mathrm{Cl})$ \\
\hline \multicolumn{4}{|l|}{ ACE } \\
\hline & $\|$ & 1.00 & 1.00 \\
\hline & ID & $1.19(0.85-1.68)$ & $1.10(0.74-1.63)$ \\
\hline & DD & $1.95(1.19-3.20)$ & $1.99(1.14-3.51)$ \\
\hline \multicolumn{4}{|l|}{ ACE2 } \\
\hline & GG & 1.00 & 1.00 \\
\hline & AA & $1.31(0.95-1.79)$ & $1.22(0.85-1.76)$ \\
\hline \multicolumn{4}{|l|}{ CYP11B2 } \\
\hline & TT & 1.00 & 1.00 \\
\hline & $\mathrm{TC}$ & $0.96(0.69-1.34)$ & $0.99(0.68-1.45)$ \\
\hline & CC & $0.75(0.41-1.37)$ & $0.64(0.32-1.28)$ \\
\hline \multicolumn{4}{|l|}{ Noise } \\
\hline & No & 1.00 & 1.00 \\
\hline & Yes & $1.57(1.13-2.17)$ & $1.52(1.04-2.22)$ \\
\hline \multicolumn{4}{|l|}{ BMI } \\
\hline & $<24$ & & 1.00 \\
\hline & $24-27$ & $2.51(1.67-3.76)$ & $2.66(1.72-4.13)$ \\
\hline & $\geq 28$ & $6.99(4.37-11.19)$ & $7.98(4.74-13.44)$ \\
\hline \multicolumn{4}{|c|}{ Family history of hypertension } \\
\hline & No & & 1.00 \\
\hline & Yes & $1.86(1.34-2.58)$ & $1.87(1.29-2.72)$ \\
\hline \multicolumn{4}{|l|}{ Education } \\
\hline & Below university & & 1.00 \\
\hline & University and above & $0.45(0.31-0.67)$ & $0.57(0.36-0.91)$ \\
\hline \multicolumn{4}{|l|}{ Eat vegetable } \\
\hline & $<3$ times/week & & 1.00 \\
\hline & $\geq 3$ times/week & $0.64(0.44-0.95)$ & $0.57(0.37-0.88)$ \\
\hline \multicolumn{4}{|l|}{ Physical exercise } \\
\hline & $<3$ times/week & & 1.00 \\
\hline & $\geq 3$ times/week & $1.51(1.05-2.17)$ & $1.54(1.00-2.36)$ \\
\hline Age & & $1.06(1.04-1.08)$ & $1.08(1.03-1.14)$ \\
\hline Length of service & & $1.05(1.03-1.07)$ & $0.99(0.94-1.03)$ \\
\hline TG & & $1.22(1.11-1.36)$ & $1.20(1.08-1.34)$ \\
\hline TC & & $0.99(0.98-1.01)$ & $0.99(0.95-1.03)$ \\
\hline
\end{tabular}

$O R^{\mathrm{a}}$ : adjusted $\mathrm{BMI}$, eduation, hypertension family history, eat vegetable, physical exercise, age, length of service, $\mathrm{TG}, \mathrm{TC}$

[18] and the T allele [19] are correlated with EH. In this study, the risk of having EH for ACE I/D DD genotype carriers was 1.99 times that for II genotype carriers $(95 \%$ CI 1.14-3.51).

Research by Kohli et al. [20] showed that there is a significant interaction effect between genes, and the risk of $\mathrm{EH}$ from the interaction of the AGT and ACE genes is significant. Niu S et al. [21] conducted a case-control study on 52 patients with $\mathrm{EH}$ and 623 patients with normal blood pressure and found that there is a strong synergy between ACE I/D and CYP11B2-344T/C. AGT6G, ACE I/D and CYP11B2 T-344C gene carriers have increased sensitivity to $\mathrm{EH}$. Understanding gene-gene interactions can greatly help with the prevention and control of $\mathrm{EH}$. In this study, the interaction between ACE2 G8790A and CYP11B2-344T/C based on the additive model showed that the two may have an interaction $(P<0.05)$. The interaction index $\mathrm{S}$ was 0.128 , suggesting that the two may have a negative interaction. When a man has the AA genotype at ACE2 G8790A, also having the $\mathrm{TC}+\mathrm{CC}$ genotype at $\mathrm{CYP} 11 \mathrm{~B} 2-344 \mathrm{~T} / \mathrm{C}$ may reduce the risk of $\mathrm{EH}$. The absolute value of AP was 0.856, suggesting that when men have the ACE2 G8790A AA genotype and the CYP11B2-344T/C TC + CC genotype, the 
Table 3 Analysis of the additive interactions between ACE, ACE2 and CYP11B2

\begin{tabular}{lllll}
\hline Genetype & Genetype & Number of EH & $\begin{array}{l}\text { Number of } \\
\text { control }\end{array}$ & OR \\
\hline ACE & CYP & & & \\
$\|$ & TT & 53 & 114 & 1.00 \\
$\|$ & TC+CC & 33 & 113 & 0.628 \\
ID +DD & TT & 69 & 148 & 1.003 \\
ID +DD & TC + CC & 69 & 126 & 1.178 \\
ACE & ACE2 & & & \\
$\|$ & GG & 37 & 121 & 1.00 \\
$\|$ & AA & 49 & 106 & 1.512 \\
ID + DD & GG & 72 & 156 & 1.509 \\
ID + DD & AA & 66 & 118 & 1.829 \\
ACE2 & CYP11B2 & & & \\
GG & TT & 58 & 164 & 1.00 \\
GG & TC + CC & 51 & 113 & 1.276 \\
AA & TT & 64 & 98 & 1.847 \\
AA & TC + CC & 51 & 126 & 1.144 \\
\hline
\end{tabular}

Table 4 Analysis of additive interactions between ACE, ACE2, CYP11B2 and noise

\begin{tabular}{llllll}
\hline Gene & Genetype & Noise & Number of EH & $\begin{array}{l}\text { Number } \\
\text { of } \\
\text { control }\end{array}$ & OR \\
& & & & 173 & 1.00 \\
ACE & $\|$ & $<80 \mathrm{~dB}(\mathrm{~A})$ & 57 & 54 & 1.630 \\
& $\|$ & $\geq 80 \mathrm{~dB}(\mathrm{~A})$ & 29 & 170 & 1.303 \\
& $\mathrm{ID}+\mathrm{DD}$ & $<80 \mathrm{~dB}(\mathrm{~A})$ & 73 & 104 & 1.897 \\
& $\mathrm{ID}+\mathrm{DD}$ & $\geq 80 \mathrm{~dB}(\mathrm{~A})$ & 65 & 204 & 1.00 \\
$\mathrm{ACE2} 2$ & $\mathrm{GG}$ & $<80 \mathrm{~dB}(\mathrm{~A})$ & 68 & 73 & 1.685 \\
& $\mathrm{GG}$ & $\geq 80 \mathrm{~dB}(\mathrm{~A})$ & 41 & 139 & 1.338 \\
& $\mathrm{AA}$ & $<80 \mathrm{~dB}(\mathrm{~A})$ & 62 & 85 & 1.871 \\
& $\mathrm{AA}$ & $\geq 80 \mathrm{~dB}(\mathrm{~A})$ & 53 & 183 & 1.00 \\
$\mathrm{CYP11B2}$ & $\mathrm{TT}$ & $<80 \mathrm{~dB}(\mathrm{~A})$ & 69 & 79 & 1.779 \\
& $T T$ & $\geq 80 \mathrm{~dB}(\mathrm{~A})$ & 53 & 160 & 1.011 \\
& $T T+C C$ & $<80 \mathrm{~dB}(\mathrm{~A})$ & 61 & 79 & 1.376 \\
\hline
\end{tabular}

Table 5 GMDR analysis for the best interaction combination models

\begin{tabular}{llll}
\hline Model & $\begin{array}{l}\text { Cross-validation } \\
\text { consistency }\end{array}$ & $\begin{array}{l}\text { Testing } \\
\text { balanced } \\
\text { accuracy }\end{array}$ & $\boldsymbol{P}^{\mathbf{a}}$ \\
\hline Noise & $10 / 10$ & 0.5527 & 0.0107 \\
ACE, ACE2 & $6 / 10$ & 0.5115 & 0.3770 \\
ACE, ACE2, CYP & $7 / 10$ & 0.4817 & 0.9453 \\
ACE, ACE2, CYP, noise & $10 / 10$ & 0.5084 & 0.3770 \\
\hline
\end{tabular}

$P^{\mathrm{a}}$ : adjusted $\mathrm{BMI}$, eduation, hypertension family history, eat vegetable, physical exercise, age, length of service, TG, TC rate of $\mathrm{EH}$ is affected by the interaction between the two is 85 . The absolute value of RERI was 0.979 , indicating that the effect of the interaction between the two on $\mathrm{EH}$ is 0.979 times that of other unknown factors. We found an ORINT of 0.485. In this study, other genes did not show any interaction based on the additive model.

Logistic regression was used to analyse the interaction between genes, and the results showed that ACE I/D and CYP11B2-344T/C polymorphisms may interact, based on the multiplicative model. The risk of having EH for ACE I/D DD and CYP11B2-344T/C TC genotype carriers was 3.04 times that for the ACE I/D II genotype and CYP11B2-344T/C TT genotype carriers (95\% CI 1.257.39). The other genotypes did not show interactions in this study, based on the multiplicative model.

Occupational noise exposure is a harmful factor for workers. Yang et al. [22] conducted a meta-analysis that showed that workers affected by noise had a higher risk of $\mathrm{EH}$ than the control group. In this study, after adjusting for factors such as BMI, family history of hypertension, TG, and TC, it was found that noise exposure increased the risk of $\mathrm{EH}$ in male workers $(\mathrm{OR}=1.52,95 \%$ CI 1.04-2.22).

It is necessary to combine genetic factors with environmental factors to explore their impact on EH. Zawilla et al. [23] found that carriers of the ACE gene AG GG DD genotype were susceptible to hypertension under noise exposure. Hwang et al. [24] conducted a 21-year cohort study on 1301 aviation workers. The study found that workers with the AGT TT genotype had a higher risk of EH when exposed to occupational noise for a long time. In our analysis of the interaction between noise and ACE, ACE2 and CYP11B2 in both the additive and the multiplicative model, no noise-gene interaction were found.

When the multivariate logistic regression method was used, there was a problem of dimensionality. For example, a small sample size and a large number of independent variables may lead to an increase in type I errors. The GMDR method can adjust the covariates to improve the accuracy of prediction. Zhang et al. [25] studied the effect of gene-gene and gene-smoking interactions of CYP4A11 single-nucleotide polymorphisms on EH. Their results showed that there was a synergy between rs1126742 and rs3890011 and between rs1126742 and smoking according to the GMDR method. The GMDR method was used in this study and showed that there was no interaction between $\mathrm{ACE}, \mathrm{ACE} 2$ and $\mathrm{CYP} 11 \mathrm{~B} 2$ and noise.

This study explored the influence of the interaction of ACE, ACE2, CYP11B2 gene polymorphisms and noise on EH. Some limitations of our research should be noted. First, the sample was not large, so the results of this study need to be verified in a study with a larger sample. 
Second, there were few gene loci typed in this study, and there are other genes related to EH in the RAAS system. In the future, more gene loci will be included to better study the relationships between hypertension and genetic and environmental factors. Finally, this study adopted a case-control research method, which may be affected by confounding factors. In the future, the scale of the research will be expanded to further study the influence of the interaction of genes and noise on $\mathrm{EH}$.

\section{Conclusions}

Noise exposure increases the risk of EH. The ACE DD genotype may be a susceptible genotype for essential hypertension. Carrying the DD genotype of ACE I/D and the TC genotype of CYP11B2-344T/C at the same time increases the risk of $\mathrm{EH}$. The significance of this study is to screen high-risk groups and provide a theoretical basis for the prevention and treatment of $\mathrm{EH}$.

\begin{abstract}
Abbreviations
EH: Essential hypertension; RAAS: Renin-angiotensin-aldosterone system; JNC 7: The seventh US Joint National Committee on Detection, Evaluation and Treatment of Hypertension; BMI: Body mass index; TC: Total cholesterol; TG: Triglyceride; TWA:Time-weighted average; CNE: Cumulative noise exposure; WBGT: Wet bulb global temperature; RFLP: Restriction fragment length polymorphism; PCR: Polymerase chain reaction; HWE: Hardy-Weinberg equilibrium; OR: Odds ratios; Cl: Confidence intervals; SPSS: Statistical Package for the Social Sciences; GMDR: Generalized multifactor dimensionality reduction; AP: Attribution proportion of the interaction; RERI: Relative excess risk of interaction; $\mathrm{OR}_{(\mathrm{INT})}$ : Interaction odds ratio; NCBI: National Center for Biotechnology Information; MAF: Minimum allele frequency; SNP: Single Nucleotide Polymorphism.
\end{abstract}

\section{Supplementary Information}

The online version contains supplementary material available at https://doi. org/10.1186/s12920-022-01177-0.

Additional file 1: Table S1. Primer Sequence of Each Gene Locus and PCR Reaction Conditions. Table S2. Primer Sequence of Each Gene Locus and PCR Reaction Conditions. Table S3. The Genotype and Allele Distributions of ACE, ACE2 and CYP11B2 Distribution in the EH Group and Control Group. Table S4. Analysis of the Multiplicative Interactions Between ACE, ACE2 and CYP11B2. Table S5. Analysis of Multiplication Interactions Between ACE, ACE2, CYP11B2 and Noise. Figure S1. The combined model of gene-noise interactions.

\section{Acknowledgements}

The authors thank all patients and control subjects for their participation. This work was supported by the Health and Family Planning Commission of Hebei, Hebei province, P.R. China (No. 20160216).

\section{Authors' contributions}

XZ carried out the experimental work and drafted the manuscript; JT participated in the design and coordinated experimental work; YW and JY carried out the data collection and interpretation; SJ designed the research survey; $J X$ and PL carried out the experimental work; QL substantively revised manuscript; ZW and $Y Z$ coordinated on-site work; FC and XL did questionnaire. All authors read and approved the final manuscript.

\section{Funding}

Funding for this study was provided by the Health and Family Planning Commission of Hebei, Hebei province, P.R. China (No. 20160216).

\section{Availability of data and materials}

The datasets generated and analyzed during the current study are not publicly available due other analyses are proceeding but are available from the corresponding author on reasonable request.

\section{Declarations}

\section{Ethics approval and consent to participate}

This research was approved by the Ethics Committee of North China University of Science and Technology (NO: 13049), and all methods were carried out in accordance with relevant guidelines and regulations. All participants gave informed consent before taking part in this study.

\section{Consent for publication}

Not applicable.

\section{Competing interests}

The authors declare that they have no competing interests.

\section{Author details}

${ }^{1}$ School of Public Health, North China University of Science and Technology, No. 21 Bohai Avenue, Caofeidian Area, Tangshan 063210, Hebei Province, People's Republic of China. ${ }^{2}$ Department of Endocrinology, North China University of Science and Technology Affiliated Hospital, Tangshan, People's Republic of China. ${ }^{3}$ Department of Public Health, North China University of Science and Technology Affiliated Hospital, Tangshan, People's Republic of China.

${ }^{4}$ Tangshan Hongci Hospital, Tangshan, People's Republic of China.

Received: 23 August 2021 Accepted: 2 February 2022

Published online: 08 February 2022

\section{References}

1. Srivastava K, Chandra S, Narang R, et al. E-selectin gene in essential hypertension: a case-control study. Eur J Clin Invest. 2018;48:e12868.

2. Lu J, Lu Y, Wang $X$, et al. Prevalence, awareness, treatment, and control of hypertension in China: data from 1.7 million adults in a populationbased screening study (China PEACE Million Persons Project). Lancet. 2017;390:2549-58.

3. Raff $H$, Bruder ED, Cullinan WE, et al. Effect of animal facility construction on basal hypothalamic-pituitary-adrenal and renin-aldosterone activity in the rat. Endocrinology. 2011;152:1218-21.

4. Reinhart GA, Lohmeier TE, Hord CE Jr. Hypertension induced by chronic renal adrenergic stimulation is angiotensin dependent. Hypertension. 1995;25:940-9.

5. Allen AM. Role of angiotensin in the rostral ventrolateral medulla in the development and maintenance of hypertension. Curr Opin Pharmacol. 2011;11:117-23.

6. Daugherty A, Poduri A, Chen X, et al. Genetic variants of the renin angiotensin system: effects on atherosclerosis in experimental models and humans. Curr Atheroscler Rep. 2010;12:167-73.

7. Hilbert P, Lindpaintner K, Beckmann JS, et al. Chromosomal mapping of two genetic loci associated with blood-pressure regulation in hereditary hypertensive rats. Nature. 1991;353:521-9.

8. Tousoulis D, Koumallos N, Antoniades C, et al. Genetic polymorphism on type 2 receptor of angiotensin II, modifies cardiovascular risk and systemic inflammation in hypertensive males. Am J Hypertens. 2010;23:237-42.

9. Freitas SR, Cabello PH, Moura-Neto RS, et al. Analysis of renin-angiotensinaldosterone system gene polymorphisms in resistant hypertension. Braz J Med Biol Res. 2007:40:309-16.

10. LiYY. Lack of Association of ACE2 G8790A gene mutation with essential hypertension in the Chinese population: a meta-analysis involving 5260 subjects. Front Physiol. 2012;3:364. 
11. Tsujita Y, Iwai N, Katsuya T, et al. Lack of association between genetic polymorphism of CYP11B2 and hypertension in Japanese: the Suita Study. Hypertens Res. 2001;24:105-9.

12. Chobanian AV, Bakris GL, Black HR, et al. The National High Blood Pressure Education Program Coordinating Committee. The Seventh Report of the Joint National Committee on prevention, detection, evaluation, and treatment of high blood pressure: the JNC 7 report. JAMA. 2003;289:2560-72.

13. Zhao YM, Zhang SZ, Robert C, et al. Investigation of dose-responserelationship between cumulative noise exposure and hypertensive prevalence in female textile workers. Chin J Ind Hyg Occup Dis. 1993;1 1:325-7.

14. Rothman KJ, Greenland S. Modem epidemiology. 2nd ed. Philadelphia: Lippincott-Raven Publishers; 1998. p. 269-73.

15. Yang YL, Mo YP, He YS, et al. Correlation between renin-angiotensin system gene polymorphisms and essential hypertension in the Chinese Yi ethnic group. J Renin Angiotensin Aldosterone Syst. 2015;16:975-81.

16. Agachan $B$, Isbir T, Yilmaz H, et al. Angiotensin converting enzyme I/D, angiotensinogen T174M-M235T and angiotensin II type 1 receptor A1 166C gene polymorphisms in Turkish hypertensive patients. Exp Mol Med. 2003;35:545-9.

17. Vamsi UM, Swapna N, Padma G, et al. Haplotype association and synergistic effect of human aldosterone synthase (CYP11B2) gene polymorphisms causing susceptibility to essential hypertension in Indian patients. Clin Exp Hypertens. 2016;38:659-65.

18. Ji X, Qi H, Li DB, et al. Associations between human aldosterone synthase CYP11B2 (-344T/C) gene polymorphism and antihypertensive response to valsartan in Chinese patients with essential hypertension. Int J Clin Exp Med. 2015;8:1173-7.

19. Rajan S, Ramu P, Umamaheswaran G, et al. Association of aldosterone synthase (CYP11B2 C-344T) gene polymorphism and susceptibility to essential hypertension in a south Indian Tamil population. Indian J Med Res. 2010;132:379-85.

20. Kohli S, Kumar R, Gupta M, et al. Impact of interactions between risk alleles on clinical endpoints in hypertension. Heart Asia. 2016;8:83-9.

21. Niu S, Zhang B, Zhang K, et al. Synergistic effects of gene polymorphisms of the renin-angiotensin-aldosterone system on essential hypertension in Kazakhs in Xinjiang. Clin Exp Hypertens. 2016;38:63-70.

22. Yang $Y$, Zhang E, Zhang J, et al. Relationship between occupational noise exposure and the risk factors of cardiovascular disease in China: a metaanalysis. Medicine (Baltimore). 2018;97:e11720.

23. Zawilla N, Shaker D, Abdelaal A, et al. Angiotensin-converting enzyme gene polymorphisms and hypertension in occupational noise exposure in Egypt. Int J Occup Environ Health. 2014;20:194-206.

24. Hwang BF, Chang TY, Cheng KY, et al. Gene-environment interaction between angiotensinogen and chronic exposure to occupational noise contribute to hypertension. Occup Environ Med. 2012;69:236-42.

25. Zhang H, Jin L, MuT, et al. Associations of CYP4A11 gene-gene and gene-smoking interactions with essential hypertension in the male eastern Chinese Han population. Clin Exp Hypertens. 2017;39:448-53.

\section{Publisher's Note}

Springer Nature remains neutral with regard to jurisdictional claims in published maps and institutional affiliations.

Ready to submit your research? Choose BMC and benefit from:

- fast, convenient online submission

- thorough peer review by experienced researchers in your field

- rapid publication on acceptance

- support for research data, including large and complex data types

- gold Open Access which fosters wider collaboration and increased citations

- maximum visibility for your research: over 100M website views per year

At BMC, research is always in progress.

Learn more biomedcentral.com/submissions 